\title{
Pounding Effect of Adjacent Buildings during Earthquake in Iraq
}

\author{
Ammar A. Abdul Rahman', Manaf Raied Salman² \\ ${ }^{1}$ Ph.D., Structural Engineering, Faculty Member, Civil Engineering Department, Al Nahrain University, Baghdad, IRAQ \\ ${ }^{2}$ M.Sc Student, Structural Engineering, Civil Engineering Department, Al Nahrain University, Baghdad, IRAQ
}

\begin{abstract}
In addition to structural destruction due to earthquakes structures and their components suffered additional destruction due to pounding. Building Pounding is defined as collision of adjacent buildings when earthquakes take place and buildings show lateral movement. In this study, different cases of typical 2-dimensional adjacent multi-story reinforced concrete buildings usually constructed in Iraqi major cities commercial centers. will be considered to study the effects due to buildings pounding when subjected to actual earthquake took place in Iraq ( like Ail Al-Gharbee ground-motion). Buildings with different height, story levels and gaps are analyzed using finite element program SAP 2000 version 16 software. The results showed that when there is no gap between adjacent buildings, the pounding forces effect increases by about (5\% to $10 \%$ ) of pounding forces when there is gap between adjacent buildings and it decreases when adjacent buildings have higher number of floors
\end{abstract}

Keywords: Earthquakes, Pounding effect, Adjacent Buildings, Finite element, SAP 2000

\section{Introduction}

Earthquakes are natural disasters of a generally unpredictable nature. In spite of considerable efforts made towards improving the understanding of these natural disasters and protecting built environment from their effects, earthquakes still cause huge human and economic losses since ancient time [1]. During earthquakes in addition to destruction due to inadequate design and performance, structures and their components suffered destruction due to pounding also. Pounding is defined as collision between two structures or different parts of the same structure leading to severe damage or even sometimes complete collapse [2]. Iraq had witnessed in recently a significant increase in seismic activity and since current regulations of municipalities in Iraq allow the use of the whole width of the lands in buildings which will lead to direct touch between adjacent buildings, this will affect the behavior of these buildings under earthquakes. Herein, the behavior and the pounding effect between adjacent buildings under actual earthquakes in area of study is investigated, and the amount of the pounding force that will be induced between the two buildings will be calculated. This is a very important parameter to be focused on in Iraq due to the way of constructing commercial buildings in Iraqi cities.

\section{Literature Review}

Anagnostopoulos, in1988, studied the effect of pounding on a number of adjacent buildings during earthquake excitation. He used the spring damper element to simulate the pounding model. He concluded that the exterior structures response (displacements) may be augmented while the interior structure may suffer augmentation or de- augmentation depending on the ratio of their natural periods [2].

Papadrakakis et al. in 1996, discussed the pounding between adjacent buildings when subjected to seismic excitation. A 3-D finite element model was used to simulate the pounding effect between adjacent buildings. They concluded that the response of the structure is directly proportional to its stiffness when the fundamental frequency of the structure is nearer to the predominant frequency range of ground motion. If it is not, the response of flexible structure is more. They also indicated that an increase in strain energy is detected due to pounding in addition to the sum of strain energies of distinct buildings in the absence of pounding [3].

C. Rajaram and R. Kumar, in 2014 performed a 3-D finite element study about pounding effect between adjacent buildings during seismic hazard using SAP 2000 software program. They studied the torsional effect due to collision of two adjacent single story reinforced concrete building models, with different setbacks and story-height levels. They concluded that the effect of impact or pounding is more when buildings are kept at maximum levels of setback, and they also found that the impact force is produced at middle height of column level than other height levels because of shear amplification [4].

\section{Case Modeling}

Numerous cases can be considered herein in order to discuss the effect of pounding between adjacent buildings with different heights and gaps during earthquakes. The main building under consideration is a 4-story building. This is the typical R.C building in commercial zones in Iraqi cities. It will be considered fixed and the adjacent buildings will be variable. 2,4and 6 -story buildings are considered as the adjacent buildings. They are also commonly used in such zones. All buildings have first story height of $4.5 \mathrm{~m}$ and 3.0 $\mathrm{m}$ for the other floors. Also all of them have the same rectangular plan of $(20.0 \times 25.0) \mathrm{m}$. It has 5 spans on $\mathrm{x}$ direction and 6 spans in y direction. There are 42 rectangular reinforced concrete columns with dimensions of $0.3 \mathrm{mx} 0.5 \mathrm{~m}$ in each floor (except ground floor which has 40 rectangular columns with 2 another circular columns with $0.3 \mathrm{~m}$ radius). All beams of the building are $0.3 \mathrm{mx} 0.3 \mathrm{~m}$ dimensions and 
slab thickness is $0.2 \mathrm{~m}$. This is the simplest representation for pounding as the cases are unlimited.

Six cases will be considered. The first case is about two similar 4-story buildings with a gap between them of $40 \mathrm{~mm}$ as generally used in Iraqi local market (maximum gap used). The second case is the same as the first one but there is no gap between the buildings (Zero). The third case is a 4-story building adjacent to a 2-story building with a gap of $40 \mathrm{~mm}$. The fourth case is the same as the third one but there is no gap between the buildings (Zero). The fifth case is a 4- story building adjacent to 6-story building with a gap of $40 \mathrm{~mm}$. The sixth case is the same as the fifth one but there is no gap between the buildings (zero). Table (1) and Figures (1), (2) \& (3) show the different modeling cases.

Table 1: Modeling Cases

\begin{tabular}{|c|c|c|c|}
\hline Case & $\begin{array}{c}\text { Main Building } \\
\text { (story) }\end{array}$ & $\begin{array}{c}\text { Adjacent Building } \\
\text { (story) }\end{array}$ & $\begin{array}{c}\text { Gap Between the } \\
\text { two buildings ( } m m \text { ) }\end{array}$ \\
\hline 1 & 4 & 4 & 40 \\
\hline 2 & 4 & 4 & 0 \\
\hline 3 & 4 & 2 & 40 \\
\hline 4 & 4 & 2 & 0 \\
\hline 5 & 4 & 6 & 40 \\
\hline 6 & 4 & 6 & 0 \\
\hline
\end{tabular}

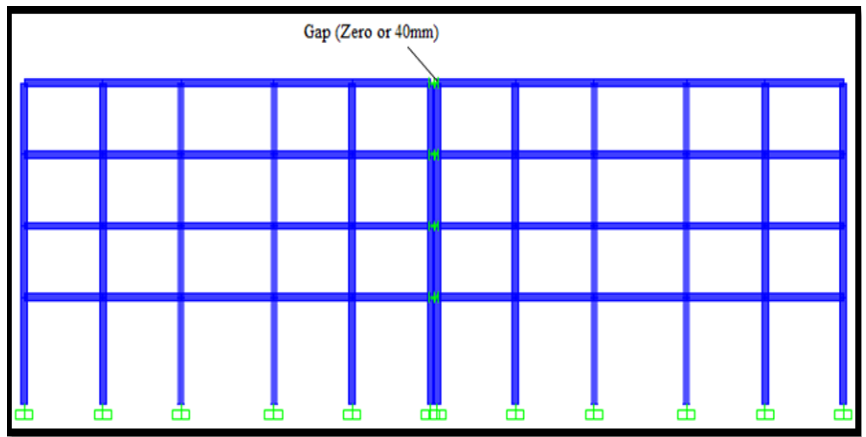

Figure 1: Two Adjacent4-Story Buildings Modeling

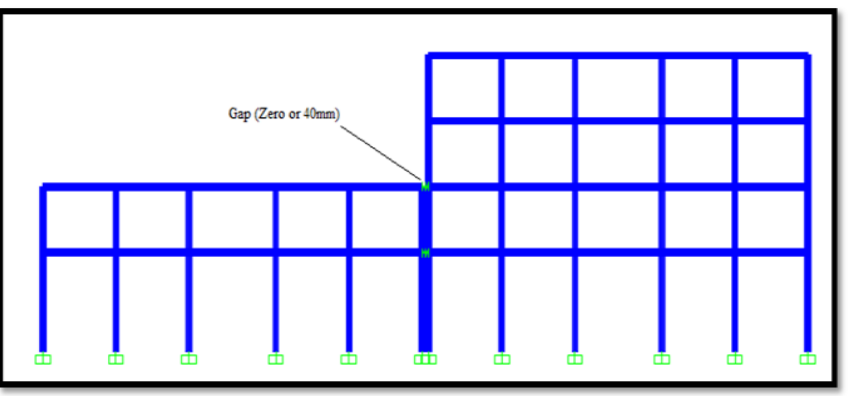

Figure 2: 4-Story Building Adjacent to 2-Story Building

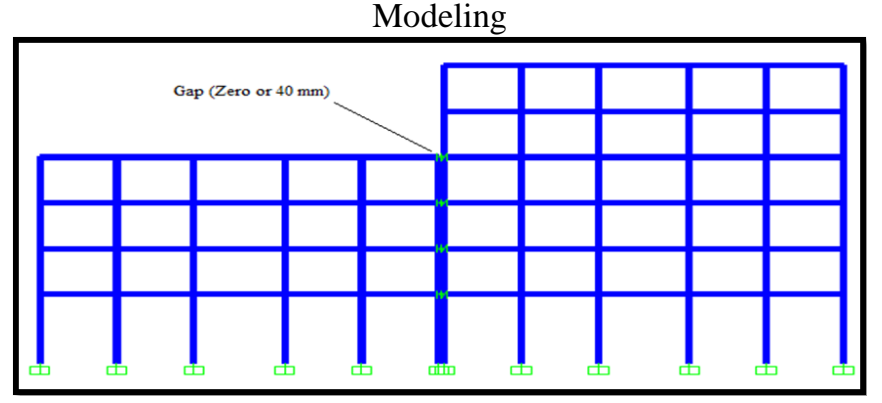

Figure 3: 4-Story Building Adjacent to 6-Story Building Modeling.

\section{Mathematical Formulation and Gap Element}

The equation of motion governing the deformation $\mathrm{u}(\mathrm{t})$ of the simple idealized structural system subjected to earthquake ground acceleration $\ddot{u}_{\mathrm{g}}(\mathrm{t})$ is[5]:

$$
[\mathrm{m}]\left\{\mathrm{u}^{\prime \prime}\right\}+[\mathrm{C}]\left\{\mathrm{u}^{\prime}\right\}+[\mathrm{K}]\{\mathrm{u}\}=-[\mathrm{m}]\left\{\mathrm{u}_{\mathrm{g}}\right\}
$$

where $[\mathrm{m}]$ is mass matrix; $[C]$ is damping matrix; $[K]$ is stiffness matrix. In order to model the collision between buildings, gap joint element is used. Gap joint element is an element which connects two neighboring nodes to represent the contact. This gets activated when buildings come closer and gets deactivated when they go away from each other.

A pounding force is produced when the two buildings come closer. This action can be modeled as shown in Figure (4). The gap element will activate if ,gap open equal to zero. The mass contributed by the link or support element is lumped at the joint $i$ in building No.1 and $j$ in building No.2 and half of the mass is assigned to the three translational degrees of freedom at each joint[5]. The results of linear analyses are based on linear effective stiffness and damping properties. The force-deformation relationship is as follows:

$$
f=\left\{\begin{array}{ccc}
(k d+\text { gap open }) & \ldots . . . \text { if } d+\text { gap open } & <0 \\
0 & \text { otherwise } & \geq 0
\end{array}\right.
$$

where, $k$ is spring constant, „gap open ${ }^{\text {ee }}$ is the gap opening which must be positive or zero and $d$ is the relative deformation across the spring. From previous research work on effect of pounding between two reinforced concrete buildings, the stiffness of gap element is $8700 \mathrm{MN} / \mathrm{m}$ [6].

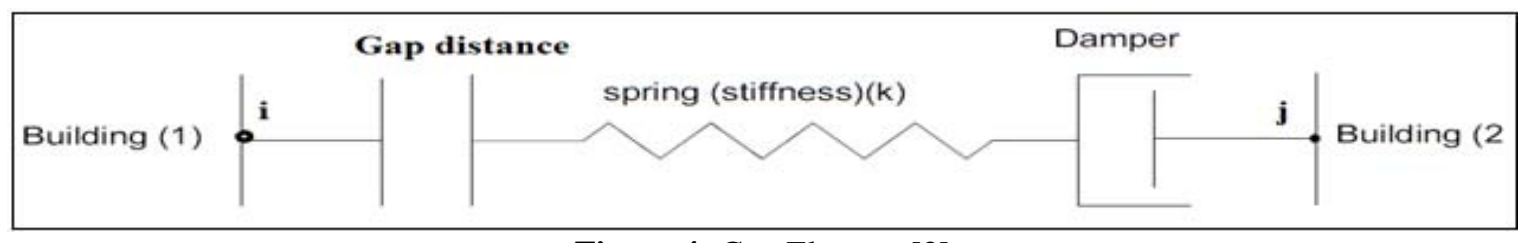

Figure 4: Gap Element [3]

\section{Numerical Results}

Due to material and geometric symmetry of the two adjacent 4-story buildings of Case 1 and Case 2, their responses to earthquake are exactly typical and there is no Perceptible pounding force between the buildings. Figure (6) shows the buildings displacement. 


\section{International Journal of Science and Research (IJSR) \\ ISSN (Online): 2319-7064}

Index Copernicus Value (2013): 6.14 | Impact Factor (2015): 6.391

For the 3rd Case when the 4-story building (right building) is adjacent to 2-story building (left building) with 40mm gap between them, the maximum story displacements of the 4story building are (34.3), (56), (72) and (80.6) $\mathrm{mm}$ for the 1st, 2nd, 3rd and 4th story respectively. Similarly the maximum story displacements of the 2-story building are (18.5) and (26.4) mm for the1st and 2nd story respectively, Figure (7) shows the time-displacement relationship of the two adjacent buildings. Also the maximum pounding forces are (24.6) and (119) $\mathrm{kN}$ for the 1st and 2nd story respectively. Figure (8) shows time-pounding force relationship.

For the 4th Case when the 4-story building (right building) is adjacent to 2-story building (left Building) with no gap between them, the maximum story displacements of the 4story building are (35), (57), (74) and (82) mm for the1st, 2nd, 3rd and 4th story respectively. Similarly the maximum story displacements of the 2-story building are (21.7) and (31) $\mathrm{mm}$ for the 1st and 2nd story respectively, Figure (9) shows the time-displacement relationship of the two adjacent buildings. Also the maximum pounding forces are (26.6) and (129) $\mathrm{kN}$ for the 1st and 2nd story respectively. Figure (10) shows time-pounding force relationship.

For the 5th Case when the 4-story building (left building) is adjacent to 6-story building (right building) with 40mm gap between them, the maximum story displacements of the 4story building are (34.2), (57), (74) and(83) mm for the1st, 2nd, 3rd and 4th story respectively. Similarly the maximum story displacements of the 6-story building are (37.7), (64.4), (87.3), (105.2), (117.3) and (123.8) for the1st, 2nd, 3rd, 4th, 5th and 6th story respectively. Figure (11) shows the timedisplacement relationship of the two adjacent buildings. Also the maximum pounding forces are (0.85), (4.8), (27.1) and (108.67) for the, 1st, 2nd, 3rd and 4th story respectively. Figure (12) shows time-pounding force relationship.

For the 6th Case when the 4-story building (left building) is adjacent to 6-story building (right building) with no gap between them, the maximum story displacements of the 4story building are (34.2), (57), (74) and (83) mm for the1st, 2nd, 3rd and 4th story respectively. Similarly the maximum story displacements of the 6-story building are (37.7), (64.4), (87.3), (105.2), (117.3) and (123.8) for the1st, 2nd, 3rd , 4th, 5 th and 6th story respectively, Figure (13) shows the timedisplacement relationship of the two adjacent building. Also the maximum pounding forces are (0.91), (5), (29) and (119.2) for the 1st, 2nd, 3rd and 4th story respectively. Figure (14) shows time-pounding force relationship. Table (2) shows pounding forces of all cases studied. Table (3) shows Shear Force at the top of columns with the effect of pounding between adjacent buildings due to original Ali Algharbee Earthquak. As it can be seen, introducing the gap between the two adjacent buildings reduced the value of the pounding force exerted at the floor levels. The adjacent building is affecting the response of the main building through collision forces where it works as a damper to the collision force as its height increases; similarly it is working as magnifier when its height decreases.
To study the effects due to buildings pounding when subjected to actual earthquake Ali ALGharbee earthquake, happened in Maysan province south of Iraq on 20 April 2013 with magnitude $\mathrm{Mw}=(4.9)$ with peak ground acceleration of $104.151 \mathrm{~cm} / \mathrm{sec}^{2}$. Input ground motions[8] for this study are shown in Figure (5).

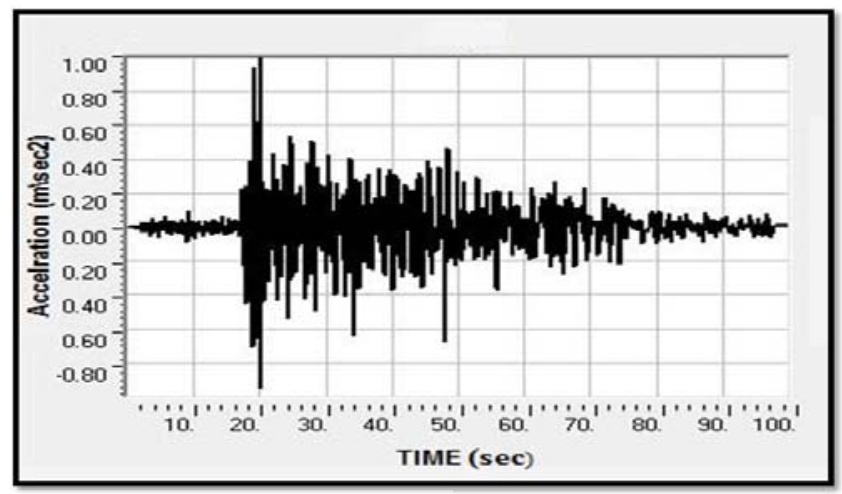

Figure 5: Ali Algarbee Acceleration-Time Plot[8]

Table 2: Pounding Forces between Adjacent Buildings due to Original Ali Algharbee Earthquake.

\begin{tabular}{|c|c|c|c|}
\hline \multicolumn{4}{|c|}{ Pounding Force(kN) } \\
\hline $\begin{array}{c}\text { Adjacent } \\
\text { Buildings }\end{array}$ & $\begin{array}{c}\text { Story } \\
\text { No. }\end{array}$ & $\begin{array}{c}\text { 40mm Gap Between } \\
\text { Buildings }\end{array}$ & $\begin{array}{c}\text { No Gap Between } \\
\text { Buildings }\end{array}$ \\
\hline \multirow{4}{*}{$4-6$} & 4 th & 108.67 & 119.2 \\
\cline { 2 - 4 } & 3rd & 27.1 & 29 \\
\cline { 2 - 4 } & 2nd & 4.8 & 5 \\
\cline { 2 - 4 } & 1 st & 0.85 & 0.91 \\
\hline \multirow{4}{*}{$4-4$} & 4th & 0 & 0 \\
\cline { 2 - 4 } & 3rd & 0 & 0 \\
\cline { 2 - 4 } & 2nd & 0 & 0 \\
\cline { 2 - 4 } & 1 st & 0 & 0 \\
\hline \multirow{3}{*}{$4-2$} & 2nd & 119 & 26.6 \\
\cline { 2 - 4 } & 1st & 24.6 & \\
\hline
\end{tabular}

Table 3: Shear Force at the Top of Columns with the effect of pounding between adjacent Buildings due to Original Ali Algharbee Earthquake

\begin{tabular}{|c|c|c|c|c|}
\hline \multicolumn{5}{|c|}{ Shear Force(kN) } \\
\hline $\begin{array}{c}\text { Adjacent } \\
\text { Buildings }\end{array}$ & $\begin{array}{c}\text { Story } \\
\text { No. }\end{array}$ & $\begin{array}{c}\text { 40mm Gap } \\
\text { Between } \\
\text { Buildings }\end{array}$ & $\begin{array}{c}\text { No Gap } \\
\text { Between } \\
\text { Buildings }\end{array}$ & $\begin{array}{c}\text { Design } \\
\text { Shear Force } \\
(\mathrm{kN})\end{array}$ \\
\hline \multirow{4}{*}{$4-6$} & 4th & 173.67 & 184.2 & 250 \\
\cline { 2 - 5 } & 3rd & 111.1 & 113 & 250 \\
\cline { 2 - 5 } & 2nd & 103.8 & 104 & 250 \\
\cline { 2 - 5 } & 1st & 103.85 & 103.91 & 250 \\
\hline \multirow{4}{*}{$4-4$} & 4th & 65 & 65 & 250 \\
\cline { 2 - 5 } & 3rd & 84 & 84 & 250 \\
\cline { 2 - 5 } & 2nd & 99 & 99 & 250 \\
\cline { 2 - 5 } & 1st & 103 & 103 & 250 \\
\hline \multirow{2}{*}{$4-2$} & 2nd & 218 & 228 & 250 \\
\cline { 2 - 5 } & 1st & 127.6 & 129.6 & 250 \\
\hline
\end{tabular}




\section{International Journal of Science and Research (IJSR) \\ ISSN (Online): 2319-7064}

Index Copernicus Value (2013): 6.14 | Impact Factor (2015): 6.391

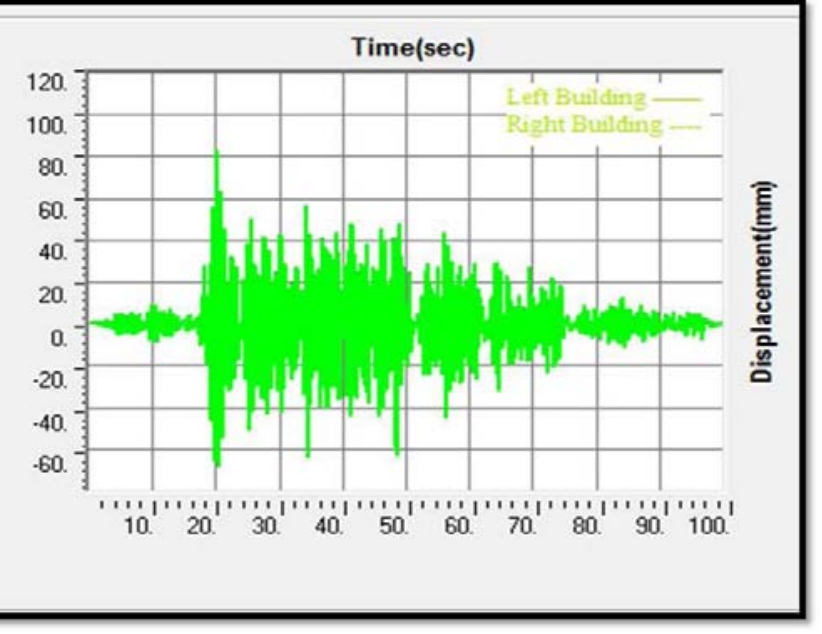

Figure 6: Time-Displacement Graph of The $1^{\text {st }}$ and $2^{\text {nd }}$ cases.

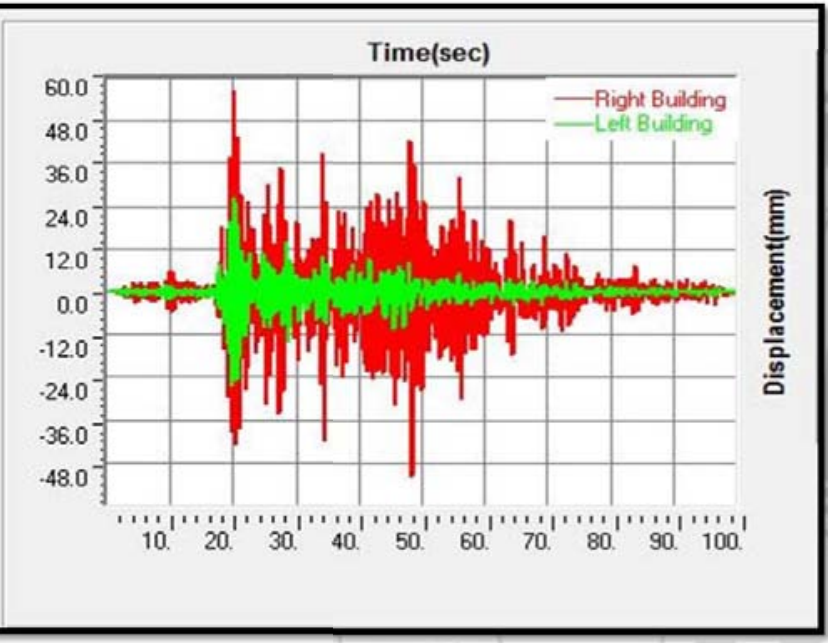

Figure 7: Time-Displacement Relationship for the $2^{\text {nd }}$ Stories of the Adjacent Buildings of The $3^{\text {rd }}$ Case.

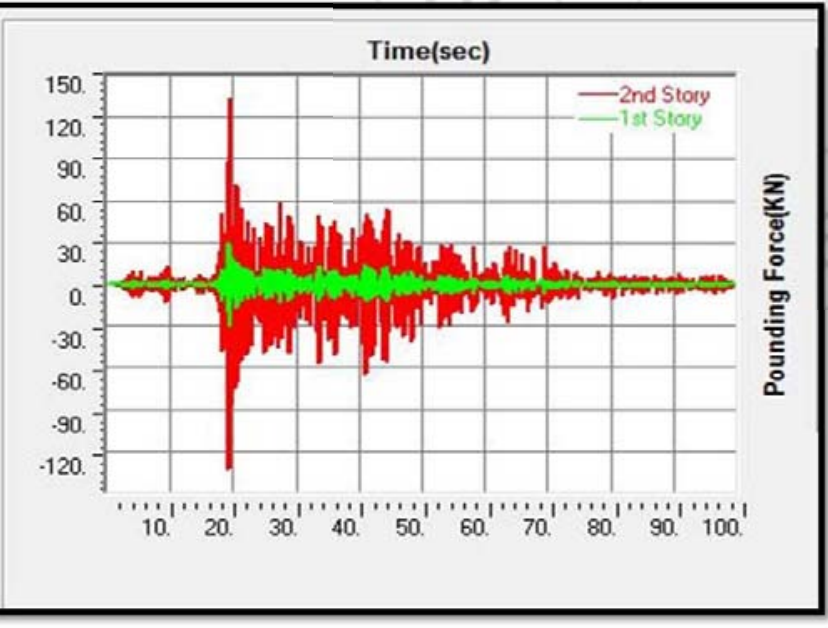

Figure 8: Time-Pounding Force Relationship for the Adjacent Buildings of The $3^{\text {rd }}$ Case.

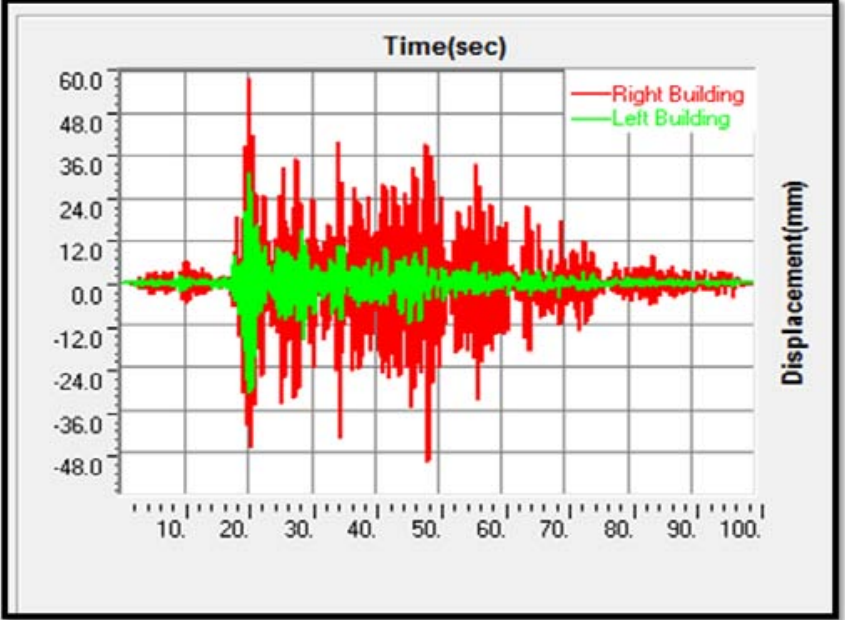

Figure 9: Time-Displacement Relationship for the $2^{\text {nd }}$ Stories of the Adjacent Buildings of The $4^{\text {th }}$ Case

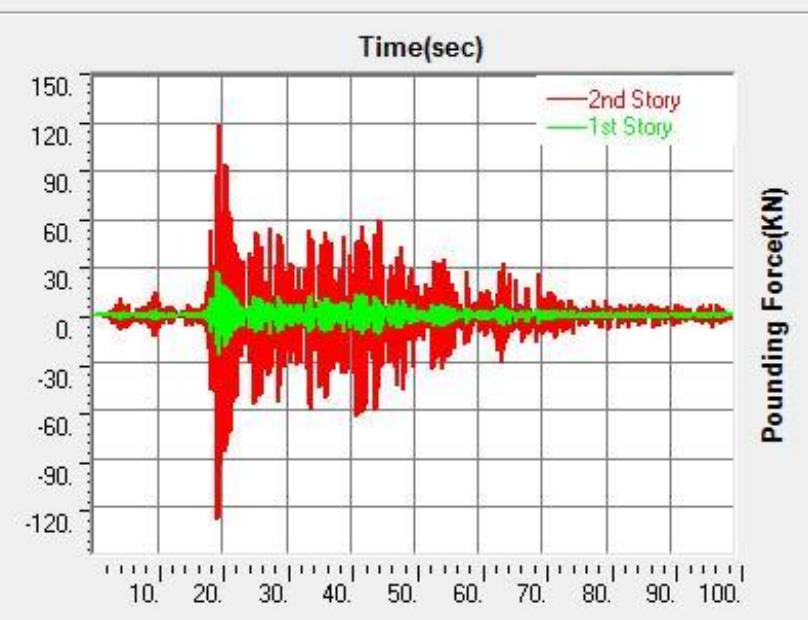

Figure 10: Time-Pounding Force Relationship for the Adjacent Buildings of The $4^{\text {th }}$ Case.

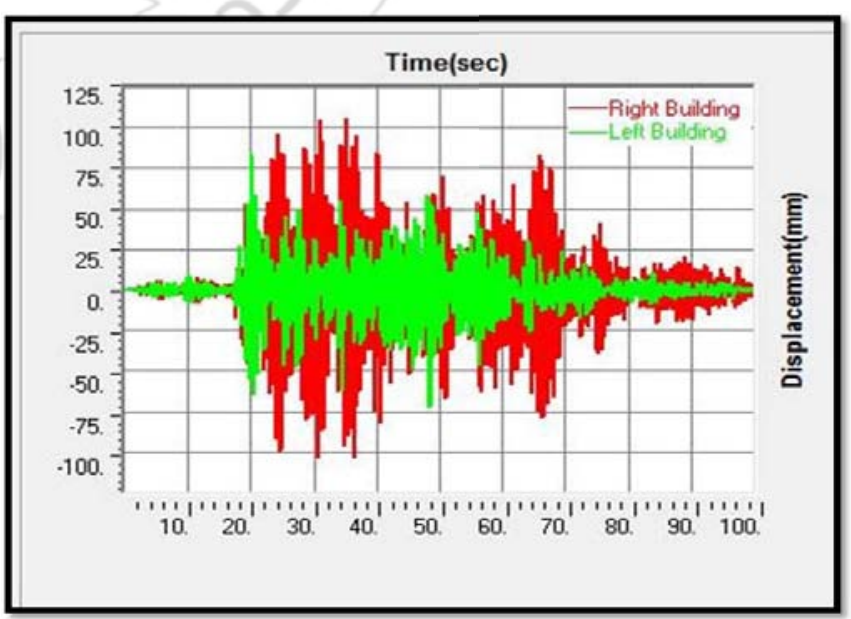

Figure 11: Time-Displacement Relationship for the $4^{\text {th }}$ Stories of the Adjacent Buildings of The $5^{\text {th }}$ Case. 


\section{International Journal of Science and Research (IJSR) \\ ISSN (Online): 2319-7064}

Index Copernicus Value (2013): 6.14 | Impact Factor (2015): 6.391

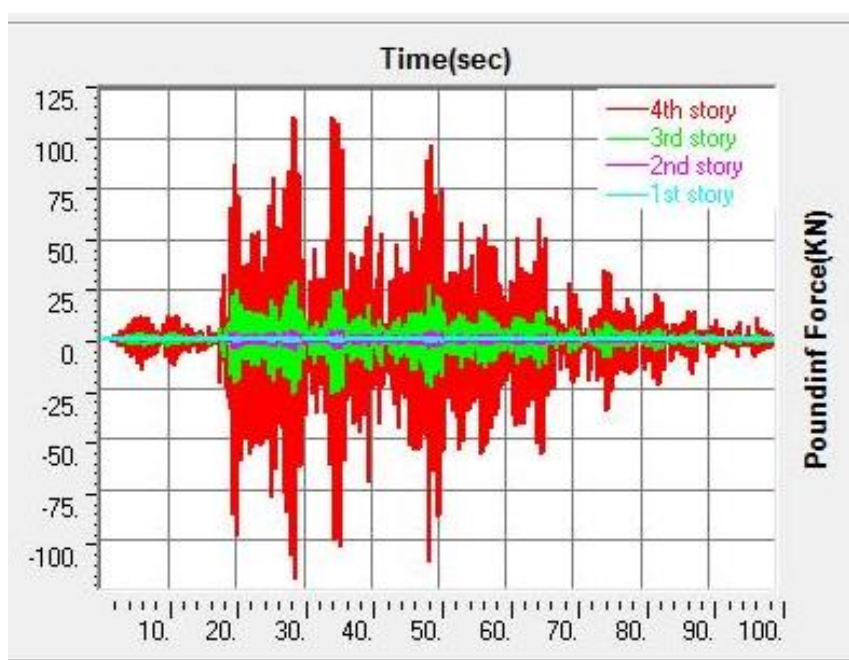

Figure 12: Time-Pounding Force Relationship for the Adjacent Buildings of The $5^{\text {th }}$ Case.

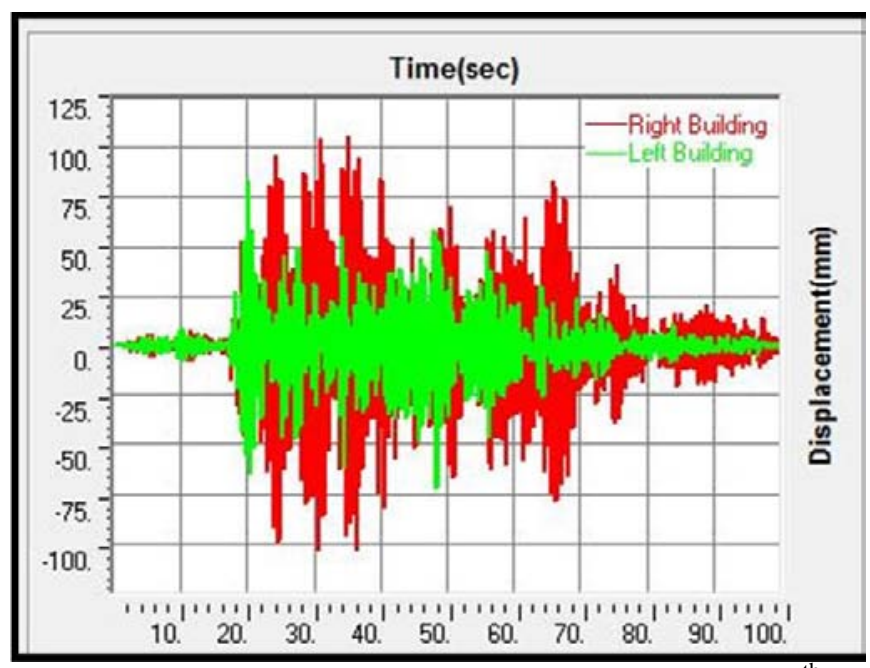

Figure 13: Time-Displacement Relationship for the $4^{\text {th }}$ Stories of the Adjacent Buildings of The $6^{\text {th }}$ Case.

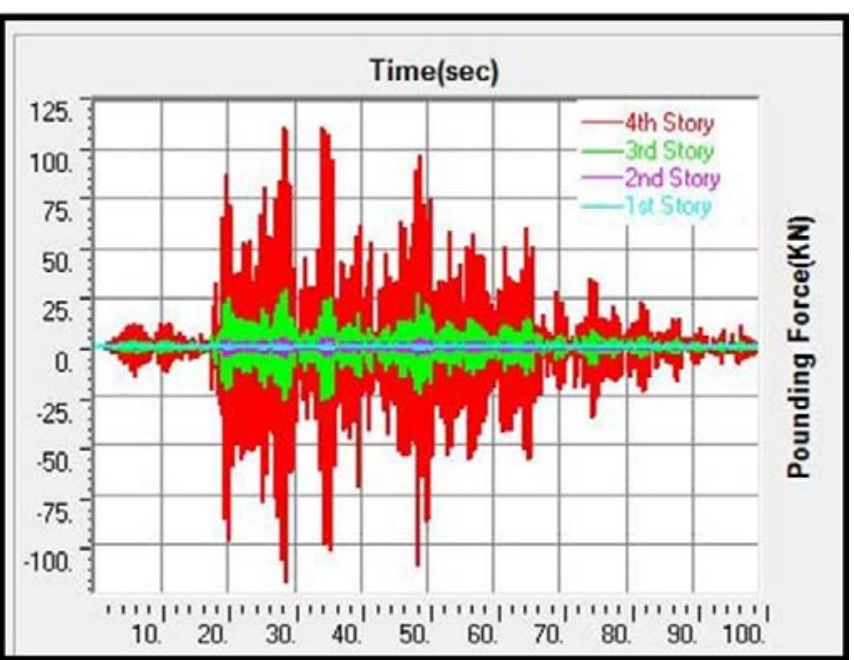

Figure 14: Time-Pounding Force Relationship for the Adjacent Buildings of The $6^{\text {th }}$ Case.

\section{Conclusions}

- The effect of pounding forces from adjacent buildings on the response and shearing forces of the building under consideration is recognized. When there is no gap between buildings which is the general case in commercial areas, the pounding forces effect will increase. It will increase the shearing forces at the top of columns near their connections to the beams where these shearing forces will reach their ultimate values even before reaching $M w=6$ Magnitude (PGA $=208 \mathrm{~cm} / \mathrm{sec}^{2}$ ) earthquake excitation.

- The effect of pounding forces from adjacent buildings with different floor levels is also recognized where higher buildings with their larger masses work as a damper to the collision forces exerted at the floor levels and lower buildings increases these forces.

- The legislations for commercial buildings at the municipalities in Iraq must take into consideration new revisions namely:

- Keeping buildings away from each other by leaving a corridor of a certain width around the building. This will end all collision forces possibilities during earthquake and helps in carrying out building services.

- Reducing the height of the ground floor columns to a safe value of less than $4.5 \mathrm{~m}$ as used now through extensive study where earthquakes will be considered to prevent the failure at the top of ground floor columns.

\section{References}

[1] Tapan K. S. (2009), "Fundamentals of Seismic Loading on Structures," John Wiley \& Sons Ltd, The Atrium, Southern Gate, Chichester, West Sussex, United Kingdom.R. Caves, Multinational Enterprise and Economic Analysis, Cambridge University Press, Cambridge, 1982.

[2] Anagnostopoulos S. A, "Pounding of Buildings in Series During Earthquakes", Earthquake Engineering and Structural Dynamic., Vol. 16, 1988, pp 443-456.

[3] Papadrakakis, M., Apostolopoulou, C., Zacharopoulos, A. and Bitzarakis, S.,(1996) "Three Dimensional Simulation of Structural Pounding during Earthquakes", Jl. of Engg. Mech., ASCE, Vol.122, pp 423-431.

[4] Rajaram, C., and Kumar, R. P.,(2014). "Three Dimensional Analysis of Pounding Between Adjacent Buildings" Journal of Structural Engineering. Vol.41, No.1, pp. 1-11.J. Geralds, "Sega Ends Production of Dreamcast," vnunet.com, para. 2, Jan. 31, 2001. [Online].

Available: http://nl1.vnunet.com/news/1116995. [Accessed: Sept. 12, 2004]. (General Internet site)

[5] Chopra, A.K. (2012), "Dynamics of Structures Theory and Applications to Earthquake Engineering" $4^{\text {th }}$ Edition, Prentice Hall.

[6] ISN, Iraqi Seismological Network. 